\title{
Análise crítica do discurso da Estratégia Nacional de Investigação e Inovação para uma Especialização Inteligente de Portugal 2014-2020
}

Critical Discourse Analysis of the National Research and Innovation Strategy for an Intelligent Specialization of Portugal 2014-2020

Analyse critique du discours portant sur la Stratégie Nationale de Recherche et d'Innovation pour une Spécialisation Intelligente du Portugal 2014-2020

Maria Cristina Ovalle Almanza e Pedro Miguel Moreira da Fonseca

\section{OpenEdition}

\section{Journals}

Edição electrónica

URL: http://journals.openedition.org/rccs/7152

DOI: $10.4000 /$ rccs.7152

ISSN: 2182-7435

\section{Editora}

Centro de Estudos Sociais da Universidade de Coimbra

Edição impressa

Data de publição: 1 setembro 2018

Paginação: 23-48

ISSN: 0254-1106

Refêrencia eletrónica

Maria Cristina Ovalle Almanza e Pedro Miguel Moreira da Fonseca, « Análise crítica do discurso da Estratégia Nacional de Investigação e Inovação para uma Especialização Inteligente de Portugal 2014-2020 », Revista Crítica de Ciências Sociais [Online], 116 | 2018, posto online no dia 31 julho 2018 , consultado o 12 setembro 2020. URL : http://journals.openedition.org/rccs/7152 ; DOI : https:// doi.org/10.4000/rccs.7152 


\author{
MARIA CRISTINA OVALLE ALMANZA, \\ PEDRO MIGUEL MOREIRA DA FONSECA
}

\title{
Análise crítica do discurso da Estratégia Nacional de Investigação e Inovação para uma Especialização Inteligente de Portugal 2014-2020
}

\begin{abstract}
O artigo procede a uma análise crítica do discurso à Estratégia Nacional de Investigação e Inovação para uma Especialização Inteligente de Portugal 2014-2O20 (ENEI). O propósito é interpretar as representações sobre o conhecimento científico e tecnológico subjacentes à ENEI e suas relações com o paradigma de desenvolvimento por si promovido, procurando discutir as correspondências com as representações da natureza, da sociedade e da educação. O trabalho apoia-se teoricamente na análise dos sistemas-mundo para articular a dimensão discursiva com a crítica normativa. A análise permitiu identificar a presença de uma conceção linear do desenvolvimento (catching up), de uma representação das pessoas, da natureza e da cultura como recursos, bem como de uma noção de conhecimento científico como um continuum de experimentação, descoberta e comercialização. Finalmente, identificou-se uma autorrepresentação de Portugal compatível com a categoria teórica da semiperiferia.
\end{abstract}

Palavras-chave: análise crítica do discurso; conhecimento científico; política científica e tecnológica; política de inovação; Portugal.

\section{Introdução}

Este artigo procura analisar as representações ${ }^{1}$ do conhecimento científico que subjazem à política nacional de investigação e inovação de Portugal, tal como são expostas na Estratégia Nacional de Investigação e Inovação para uma Especialização Inteligente de Portugal 2014-2020 (ENEI). Além disso, procura-se também analisar e avaliar as relações das referidas representações com o paradigma de desenvolvimento promovido pela ENEI e sua relação com as representações da natureza, da sociedade e da educação que lhe correspon-

\footnotetext{
${ }^{1}$ As representações sociais serão entendidas, parafraseando Marková (2006), como a síntese das explicações que emergem e são reproduzidas pela comunicação intersubjetiva e que constituem um tipo específico de conhecimento que afeta o modo como as pessoas pensam e organizam a sua vida quotidiana, geralmente denominado "senso comum".
} 
dem. O pressuposto para esta análise é o de que o exercício do poder sobre e através do conhecimento científico tem uma dimensão discursiva expressa nas políticas públicas nessa matéria, pelo qual a sua compreensão só pode situar-se num horizonte crítico.

A Análise Crítica do Discurso (ACD) como opção metodológica, particularmente na perspetiva da linguística crítica de Fairclough (2001, 2003) e de Fairclough e Fairclough (2012), e a análise dos sistemas-mundo (Wallerstein, 1974, 1979, 1991, 1995, 2005), como teoria social, permitem identificar na ENEI uma conceção linear do desenvolvimento como catching up, uma representação das pessoas, da natureza e da cultura como "recursos" e um entendimento do conhecimento científico como um continuum de experimentação, descoberta e comercialização. Como resultado desta interpretação, este artigo argumenta que as políticas nacionais de ciência, tecnologia e inovação (CTeI) são uma manifestação discursiva de determinados projetos de desenvolvimento orientados por considerações ideológicas.

O artigo está organizado em quatro grandes momentos. Em primeiro lugar, descreve-se a perspetiva teórica que o orienta, centrada na discussão da noção de "desenvolvimento" e na perspetiva teórica dos sistemas-mundo. Num segundo momento, desenvolvem-se considerações sobre as origens históricas das políticas de CTeI e discute-se sumariamente o caso português. Num terceiro momento, apresentam-se as considerações metodológicas que orientaram a ACD e procede-se à análise da política portuguesa em CTeI. Finalmente, apresentam-se as principais conclusões sobre os propósitos e os fins dessa política.

\section{Desenvolvimento e análise dos sistemas-mundo}

O conceito de desenvolvimento não apenas ilustra os ideais historicistas das sociedades desde as origens da modernidade, como também fornece um guia para interpretar as configurações hierárquicas das relações entre os países na ordem global. A análise dos sistemas-mundo, formulando uma crítica às perspetivas tradicionais acerca do desenvolvimento, incorpora lições importantes a propósito destas configurações hierárquicas, a saber:

a) Do paradigma da modernização extrai a crítica ao historicismo, à sociologia funcionalista (So, 1990), à ideia do desenvolvimento como catching up e à compartimentação da realidade social (Wallerstein, 1991), elemento este constitutivo de uma ideologia liberal que influenciou a configuração e a institucionalização da atividade científica das ciências sociais (Wallerstein, 1995). A análise dos sistemas-mundo supõe, assim, uma rejeição do positivismo e da disciplinaridade das ciências sociais, contribuindo para 
uma leitura crítica da problemática do objeto de estudo consistente com a opção metodológica que orienta a análise crítica.

b) Do desenvolvimentismo, a análise dos sistemas-mundo incorpora as categorias centro e periferia para explicar as hierarquias que resultam da divisão internacional do trabalho (So, 1990), apontando para a dimensão histórica dessa divisão, que permite compreender os processos que, ao longo dos últimos 600 anos, deram forma à moderna economia-mundo.

c) Do dependentismo, a análise dos sistemas-mundo destaca a natureza estrutural do subdesenvolvimento, defendendo que o desenvolvimento é um discurso ideológico que supõe o subdesenvolvimento e a dependência. Daí que, para Wallerstein (1974), a mobilidade ascendente na hierarquia da economia-mundo represente não uma melhoria qualitativa, mas uma participação bem-sucedida nos ganhos desiguais da economia-mundo em detrimento de outras instâncias do sistema.

$\mathrm{Na}$ perspetiva da análise dos sistemas-mundo, o problema fundamental que obriga à contestação da noção de desenvolvimento relaciona-se com a própria estrutura de distribuição dos ganhos e recompensas promovida pela economia-mundo capitalista. As possibilidades de transformação estrutural da participação que as economias periféricas têm nos ganhos do comércio internacional estão drasticamente limitadas, "uma vez que a disparidade das recompensas é a força motivadora fundamental da operação do sistema tal como está construído" (Wallerstein, 1979: 73).

A análise dos sistemas-mundo procura compreender os processos históricos que têm constituído a economia-mundo capitalista, que é a forma moderna do sistema-mundo. ${ }^{2}$ Para isso, tem em conta as dinâmicas económicas e as relações de poder, assim como a correspondência entre as ditas dinâmicas e a forma tipicamente moderna de conhecer e intervir no mundo e na sociedade. Nesta perspetiva, a unidade básica de análise é o sistema-mundo, uma vez que é teoricamente inviável isolar os fenómenos sociais do conjunto de interações que os condicionam, razão pela qual Wallerstein (1974: 7) argumenta que "o único sistema social [...] [é] o sistema-mundo". Este, por sua vez, tem assumido duas formas: os impérios-mundo e a economia-mundo. Enquanto os primeiros se caracterizam por terem um único centro de poder, a economia-mundo não está limitada por uma estrutura política unitária. Ela é "uma grande zona geográfica dentro da qual existe uma divisão do trabalho e, portanto,

\footnotetext{
${ }^{2}$ Segundo Wallerstein (1974: 15), o sistema-mundo recebe a sua denominação "não por abranger o mundo inteiro, mas porque é maior do que qualquer unidade política juridicamente definida. E é uma economia-mundo porque a ligação básica entre as partes do sistema é económica, embora esteja reforçada em certa medida por ligações culturais, [...] por disposições políticas e até por estruturas confederadas".
} 
uma troca significativa de bens básicos ou essenciais, assim como um fluxo de capital e de trabalho" (Wallerstein, 2005: 21).

Outra característica da economia-mundo capitalista é a existência de hierarquias definidas e funções preestabelecidas pela divisão internacional do trabalho e, como consequência, a escassa margem de manobra dos Estados. De facto, a divisão internacional do trabalho é o elemento fundamental que configura as relações de poder entre o centro, a periferia e a semiperiferia. Para cada uma destas instâncias foram "atribuídos papéis económicos específicos, desenvolvidas diferentes estruturas de classe, utilizados diferentes modos de controlo do trabalho, bem como explorados desigualmente os ganhos provenientes do trabalho no sistema" (Wallerstein, 1974: 162).

Nos Estados centrais da economia-mundo, a criação de um aparelho de Estado forte e de uma economia nacional tem a dupla função de encobrir as desigualdades que são produto do próprio sistema e de justificar ideologicamente a existência dessas desigualdades. As áreas periféricas caracterizam-se por um Estado muito fraco ou inexistente (como no caso do colonialismo), ou um Estado que, apesar de existir formalmente, carece de autonomia (que é a marca distintiva de uma situação neocolonial). Finalmente, as áreas semiperiféricas são as que apresentam uma maior complexidade das atividades económicas, maior força do aparelho estatal e da coesão cultural e contribuem para desviar parcialmente as pressões dirigidas aos Estados centrais a partir das áreas periféricas (Wallerstein, 1974).

Porém, os conceitos de centro e periferia não operam apenas à escala global, o que significaria que no centro se concentraria em termos absolutos o bem-estar social, enquanto que na periferia estariam as populações marginalizadas. $\mathrm{Na}$ realidade, as áreas periféricas são categorias geoeconómicas e a sua constituição resultou de um processo histórico longo e complexo.

Neste contexto, é necessário explorar o papel que corresponde ao conhecimento científico na prática concreta das relações de poder na economia-mundo. Isto porque, segundo Santos, a política científica nasceu em resposta à necessidade social de orientar o desenvolvimento da ciência, orientação essa que, no contexto das sociedades industriais, equivale à procura de um certo tipo de ciência e que é "parte integrante da luta política global" (1978: 46).

\section{As políticas nacionais de CTel}

Apenas ao longo do século Xx, em particular depois da Segunda Guerra Mundial, é que se tornou claramente evidente a importância da investigação científica para a consecução de propósitos económicos e políticos dos Estados, desde logo associados ao bem-estar social e aos interesses nacionais. No caso dos Estados Unidos da América, por exemplo, à medida que o Estado estimulou 
o progresso científico, inicialmente no campo militar e posteriormente em todo o âmbito da produção de bens (Brandão, 2012), tornou-se evidente a confluência, num único sistema, da "ciência, da técnica e da revalorização do capital" (Habermas, 2013b: 73).

Durante os anos sessenta do século XX verificou-se a entrada dos economistas no campo das políticas públicas em geral e da política científica em particular, reforçando a importância da ciência e da tecnologia para o crescimento económico e o bem-estar social, e já não apenas para o sucesso no âmbito militar (Rollo et al., 2012; Brandão, 2012). Como consequência da participação do saber técnico na formulação de políticas públicas, associadas à promessa de bem-estar social, o diálogo entre a ciência e a política tornou-se ainda mais complexo: por um lado, verificou-se um processo de burocratização dos sistemas de investigação e, por outro, implementou-se uma racionalidade científica de tipo instrumental (Habermas, 2013a) na tomada de decisões políticas. Nesta medida, "o sujeito científico desempenha um papel de consultor técnico, esvaziando-se o espaço crítico e dialético da ciência e contribuindo-se para a crescente 'expertização' da política que serve, assim, à gestão das relações sociais e à despolitização das dinâmicas sociais” (Castro et al., 2013: 6).

\section{As origens da política de ciência em Portugal}

No caso de Portugal, a narrativa sobre o papel determinante do país na expansão da ciência moderna pela via das descobertas (Fiolhais, 2011) convive com a evidência histórica da hostilidade da igreja católica perante as revoluções científicas, a qual manteve o país afastado das dinâmicas da Ilustração (Nunes e Gonçalves, 2001).

Já no período do Estado Novo, o interesse pela regulação da prática científica continuava a responder apenas às necessidades de controlo e exploração dos territórios submetidos à administração colonial, necessidades que tinham mobilizado primeiro a botânica e as ciências agrárias (Freyre, 1961) e, posteriormente, a antropologia e outras ciências sociais (Roque, 2001). Aliás, os efeitos do regime "de inspiração fascista, hierárquico e paternalista" (Gonçalves, 2001: 177), sentiram-se na organização pública da ciência mesmo depois da chegada da democracia (Gonçalves, 1996), sendo apenas aliviados pela participação de Portugal no processo de integração europeia.

Esta participação teve consequências positivas na política de ciência, como o reposicionamento da investigação científica como base do desenvolvimento e o consequente incremento da sua visibilidade. No entanto, teve também implicações negativas, quer no âmbito do financiamento estatal, quer no âmbito da definição dos problemas e programas de investigação, o que resultou numa alta dependência, quer dos fundos comunitários para 
o financiamento da investigação, quer das "reputações científicas das redes transnacionais" (Nunes, 2002: 194).

Da participação de Portugal no processo de integração europeia resultaram, finalmente, consequências epistémicas, desde logo associadas à supressão das especificidades locais dos resultados de investigação. Tais características são, aliás, próprias de uma experiência periférica da ciência que privilegia a obtenção de resultados considerados pelos países centrais como generalizáveis e reproduzíveis (Castro et al., 2013: 13).

Em síntese, na história recente de Portugal, as principais características da política científica portuguesa e do tipo de relação que ela promoveu entre a ciência e a sociedade foram: (1) a baixa responsabilização do Estado "enquanto agente de redistribuição dos recursos necessários à atividade científica" (ibidem: 11); (2) a elevada dependência dos fundos europeus e das "reputações científicas das redes transnacionais" (Nunes, 2002: 194); e (3) a baixa participação da sociedade civil.

Segundo Godinho (2007) a experiência dos finais do século Xx e inícios do século XXI teve também como resultado o reconhecimento da importância de um sistema de avaliação sólido para a análise do desempenho de Portugal em atividades de CTeI. Particularmente, reconhece-se atualmente a necessidade de uma abordagem sistémica, que considere todas as etapas abrangidas no processo de geração e uso do conhecimento e que, ao mesmo tempo, esteja baseado num sólido quadro analítico, fundamentado teoricamente.

Vale a pena acrescentar a esta perspetiva o ponto de vista da própria União Europeia sobre a situação de Portugal nesta matéria, no contexto da estratégia Europa 2020. Esta estratégia foi formulada como iniciativa conjunta para a superação dos efeitos económicos, políticos e sociais da crise financeira que se iniciou em 2008. A inteligência, a sustentabilidade e a inclusão económica são os propósitos fundamentais desta estratégia que tem, para esse fim, cinco objetivos: emprego, inovação, educação, inclusão social, clima e energia (Comissão Europeia, 2010).

Sob o pressuposto de que uma economia inteligente exige um elevado grau de desenvolvimento da investigação científica e da inovação, foi incluída, como iniciativa emblemática, a "União da Inovação", orientada especificamente para o fortalecimento desta dimensão específica do desenvolvimento. De forma a contribuir para esse propósito, em 2013 a Fundação para a Ciência e a Tecnologia de Portugal (FCT) elaborou o Diagnóstico do sistema de investigação e inovação: desafios, forças e fraquezas rumo a 2020 (FCT, 2013).

Nesse diagnóstico a FCT identificou que, embora Portugal tenha feito um esforço importante em matéria de recursos para investigação e desenvolvimento da inovação durante o período de 2000-2010, os resultados 
desse esforço ainda não se refletiram em benefícios de natureza económica para o país (ibidem).

O Diagnóstico insiste que, apesar de ter atingido os objetivos propostos em termos de publicações e de "recursos humanos", a incidência tecnológica e a "intensificação tecnológica da economia" não satisfazem as expectativas, defendendo que "a economia portuguesa apresenta um claro perfil de especialização em atividades económicas de baixa ou média baixa intensidade tecnológica, particularmente concentradas no norte e centro do país" (ibidem: 10). Daí a importância da Especialização Inteligente de Portugal, estratégia refletida na sua política de CTeI e que será objeto de análise neste trabalho.

\section{Metodologia para a análise crítica do discurso da política portuguesa de CTel}

Centrada nos problemas sociais e, particularmente, no papel desempenhado pelo discurso na produção e reprodução das relações de dominação, a ACD rejeita as pretensões de neutralidade valorativa que foram consideradas critérios essenciais de cientificidade para as ciências sociais nos séculos XIX e XX.

Trata-se de um "tipo de investigação analítica do discurso que estuda primeiramente a forma como o abuso de poder social, a dominação e a desigualdade são utilizados, reproduzidos e combatidos através da linguagem oral e escrita, no contexto social e político" (Van Dijk, 2001a: 352).

Assim, "a análise crítica do discurso pode ser definida como fundamentalmente preocupada com a análise das relações estruturais, quer opacas, quer transparentes, de dominação, discriminação, poder e controlo, que se manifestam na linguagem" (Wodak, 2001: 2). O seu interesse na desigualdade social e nos mecanismos que a legitimam faz com que a ACD seja uma perspetiva de investigação "parcial e orgulhosa de o ser" (Van Dijk, 2001b: 96).

No que diz respeito às etapas gerais da investigação, o alcance do processo investigativo que aqui se descreve foi estabelecido com base nas propostas de Jäger (2001), Fairclough (2003) e Reisigl (2008):

1. Identificação de uma problemática social com uma dimensão linguística.

2. Caracterização e contextualização da área na qual se localiza o estudo e do tipo de documentos que serão analisados.

3. Definição e preparação dos materiais para a análise.

4. Análise crítica do discurso de cada um dos documentos:

a) Identificação da estrutura e das características gerais do documento e do vocabulário nele contido.

b) Estudo das características linguísticas dos textos e apresentação de resultados.

Para a análise crítica dos textos foram identificadas características linguísticas, as quais podem ser organizadas em três grupos. Num primeiro grupo 
situam-se aquelas que permitem identificar a natureza dos enunciados e as suas generalidades. Entre elas, destacam-se o modo gramatical (declarativo, interrogativo, imperativo e imperativo negativo), as relações de sinonímia, antonímia e hiponímia, e as relações semânticas (causalidade, condicionalidade, temporalidade, adição) (Fairclough, 2003). Num segundo grupo aparecem as características que evidenciam as motivações dos textos e as suas relações com outros textos e discursos. Neste grupo consideramos textos exortatórios (que, com base em avaliações implícitas, promovem formas de atuação), a articulação ou mistura de discursos (e.g. discurso liberal/discurso motivacional), definições persuasivas, declarações avaliativas, chamamentos, metas, relações meios-fins, bem como as associações (positivas e negativas) pré-construídas e formas de representação (recontextualização) dos eventos sociais (Fairclough, 2003; Fairclough e Fairclough, 2012). Finalmente, existe um terceiro grupo de características linguísticas que constituem o núcleo da análise crítica e que fornecem mais oportunidades para estabelecer relações entre os textos e a teoria social crítica. Aqui importa considerar, em primeiro lugar, a nominalização e o uso da voz passiva, desde logo com a transformação de verbos em substantivos e a deslocação do sujeito, e, em segundo lugar, a intertexualidade e a dialogicidade, desde logo com as referências a outros textos por citação explícita, modalizada ou categórica, bem como as assunções. Estas últimas, por sua vez, podem ser existenciais, proposicionais, de valor e implicações lógicas (Fairclough, 2003).

A nossa análise considera também as estratégias de legitimação, as quais podem ser: a autorização, a racionalização, a avaliação moral, a mitopoese, o estado de exceção, a atribuição da culpa, a não existência de opções alternativas, o apelo às emoções, a efetividade, a autorrepresentação positiva e a representação negativa do outro (Fonseca e Ferreira, 2015), a utilização de narrativas, a linguagem profética e o futuro hipotético (Graham, 2001).

Os enunciados podem ainda apresentar diferentes níveis de abstração, correspondendo o nível superior à representação de práticas sociais. Num nível intermédio, encontramos o conjunto de eventos sociais. Por fim, o nível mais concreto é o da representação de eventos sociais específicos. Do mesmo modo, os atores sociais podem ser representados de diferentes maneiras, podendo ser incluídos de forma explícita (como participantes nas ações, como um pronome pessoal ou possessivo, como ativo ou passivo na ação, e de forma pessoal ou impessoal), ou podem ser excluídos por meio de supressão ou de forma implícita (Fairclough, 2003).

Quando um processo é representado metaforicamente como uma entidade e o seu papel semântico é o de um sujeito, podemos falar em metáforas processuais ou gramaticais, por oposição às metáforas lexicais, nas quais um objeto é representado por referência a outro (Graham, 2001). A “modalização", 
por sua vez, indica o nível de compromisso com a verdade dos resultados, podendo esse ser alto ("certamente", "é necessário"), intermédio ("provavelmente", "é suposto") ou baixo ("possivelmente", "é permitido"). Finalmente, nos textos é possível identificar valores subjacentes aos enunciados (Fairclough, 2003). As características anteriormente descritas permitiram operacionalizar a análise crítica que seguidamente se apresenta.

\section{Análise crítica da Estratégia Nacional de Investigação e Inovação para uma Especialização Inteligente 2014-2020}

A Estratégia Nacional de Investigação e Inovação para uma Especialização Inteligente 2014-2020 (ENEI) enquadra-se na iniciativa emblemática "União da Inovação", através da qual a Comissão Europeia orienta a transformação da Europa numa "economia baseada no conhecimento e na inovação". Esta iniciativa emblemática, por sua vez, corresponde à primeira das três prioridades identificadas pela própria Comissão na estratégia Europa 2020, com vista à superação dos efeitos da crise financeira e à construção de uma economia europeia "inteligente, sustentável e inclusiva": a) crescimento inteligente; b) crescimento sustentável; c) crescimento inclusivo (Comissão Europeia, 2010).

De facto, toda a política de coesão da União Europeia 2014-2020 participa da abordagem conhecida como place-based policy. Esta abordagem insiste na importância do contexto geográfico e das interações entre esse contexto e as características sociais, culturais e institucionais das regiões como elementos fundamentais para o desenho e a implementação de políticas públicas de desenvolvimento (Barca et al., 2012). As políticas públicas place-based têm como foco as necessidades e potencialidades do território e a sua população, descentralizando o poder decisório, empoderando os atores locais (Santos et al.,2015) e apresentando, segundo os seus defensores, maior eficácia e eficiência do que as políticas espacialmente "neutras" (Barca et al., 2012).

$\mathrm{Na}$ realidade, as Estratégias Nacionais e Regionais de Especialização Inteligente, enquanto políticas place-based, são parte integrante de uma estratégia de articulação entre os níveis regional, nacional e supranacional. Nesta perspetiva multinível, as ENEI e EREI (Estratégias Regionais de Especialização Inteligente) visam direcionar o apoio político e o investimento financeiro para promover o desenvolvimento de base científica e tecnológica (Comissão Europeia, 2014). Segundo Midtkandal e Sörvik (2012), o objetivo último desta forma de atuação consiste em garantir o crescimento económico na Europa, para o qual os fundos estruturais são uma ferramenta chave. É nesse contexto que foi introduzida a ideia da especialização inteligente.

Interessada em agilizar o processo de transferência de conhecimentos e em fortalecer o estímulo ao empreendedorismo em áreas de intensidade tecnológica 
(Oliveira, 2015), a especialização inteligente aspira a fortalecer as relações entre a investigação científica e os setores económicos (Foray et al., 2011). Nesse sentido, a ideia de processo de descoberta empreendedora desempenha um papel relevante, uma vez que ele é o mecanismo que permite identificar, através de exercícios de aprendizagem coletiva, as áreas de inovação nas quais uma região ou país tem maiores oportunidades de sucesso (Foray et al., 2009).

No entanto, a ideia de especialização inteligente não está isenta de consequências políticas. Em primeiro lugar, porque ela é, nas palavras da própria Comissão Europeia, "uma atualização da metodologia existente para a programação dos Fundos Estruturais", baseada "no pensamento económico vanguardista das grandes instituições internacionais, como o Banco Mundial, a OCDE e o FMI" (Comissão Europeia, 2014: 6). Em segundo lugar, porque embora o conceito rejeite a divisão do trabalho entre produtores e utentes do conhecimento (Foray et al., 2011) a sua implementação supõe a diferenciação entre regiões e Estados "líderes" e regiões e Estados "seguidores" (Foray et al., 2009). Esta separação defende a ideia segundo a qual às regiões "seguidoras" corresponde uma forma de participação denominada "co-invenção de aplicações", isto é, a introdução das tecnologias criadas pelas regiões "líderes" nos setores - até então-de menor intensidade tecnológica que constituem a sua base económica.

Este "ambiente competitivo mais realista" (ibidem: 22), criado pela especialização inteligente, reproduz as assimetrias existentes entre países e regiões, ao mesmo tempo que desestimula o investimento público em atividades como a educação superior e a investigação básica. Adicionalmente, quando articulado no contexto da abordagem conhecida como place-based policy, o discurso político subjacente à especialização inteligente vem reforçar a ideia segundo a qual o subdesenvolvimento "que limita e inibe o potencial de crescimento das regiões ou que perpetua a exclusão social [é] o resultado de uma falha na ação das elites locais e só pode ser remediado através de novo conhecimento e de novas ideias" (Barca et al., 2012: 139). Esta e outras consequências políticas da perspetiva teórica desta política pública serão objeto da análise crítica que se apresenta a seguir.

\section{Estrutura e características gerais do documento e metodologia}

No seguimento do que foi referido anteriormente, a ENEI tem por objetivo "promover uma evolução coerente e adequada do sistema de I\&I, no seu conjunto, e dos sistemas regionais e sectoriais de inovação, que fazem parte daquele" (IAPMEI et al., 2014: 63). Para atingir esse objetivo, a estratégia articula "grandes apostas", ou seja, aquelas que gerariam maiores benefícios em caso de o investimento - quer público, quer privado - ser direcionado para elas, em função da especialização inteligente do país. 
Em termos metodológicos, tanto a política como a análise SWOT que lhe serve de ponto de partida foram realizadas com a participação dos atores envolvidos nas atividades de investigação e inovação. Em coerência com a orientação bottom-up que caracteriza a especialização inteligente, a ENEI foi formulada através de numerosos exercícios participativos que representaram uma inovação nos mecanismos de formulação de política pública na história portuguesa. Aliás, o próprio Plano Tecnológico para 2005-2009 em Portugal tinha já ensaiado uma governação em rede (network governance) que contrastou de forma evidente com as estruturas corporativas fechadas, assim como com as divisões e dependências verticais que caraterizaram a governação das políticas de inovação no passado em Portugal (Laranja, 2012).

No entanto, na distribuição destes atores verifica-se que, embora o documento afirme que esta distribuição "deveria de ser dividida equitativamente" (IAPMEI et al., 2014: 110), ela apresenta uma participação muito maior das empresas do setor privado ( $9 \%$ observadores, $39 \%$ academia e $52 \%$ empresas) (ibidem: 113 ). Do mesmo modo, quando se avalia a distribuição dos atores por setor institucional, verifica-se o predomínio das empresas do setor privado - Estado: 10\%, IPSFL: $18 \%$, ensino superior: $26 \%$, empresas: $46 \%$ (ibidem: 114 ). Esta característica revela-se importante, na medida em que condiciona a identificação dos objetivos e eixos temáticos da estratégia, bem como influencia as próprias conceções de inovação, educação e conhecimento científico subjacentes à política.

\section{A linguagem na ENEI}

Outra característica relevante do documento diz respeito à própria linguagem utilizada na sua redação e que se revela fundamental para a análise crítica do discurso desta política. Nesta matéria, interessa destacar dois aspetos principais: (1) o elevado nível de abstração que caracteriza o documento; (2) o uso frequente de palavras em inglês para a designação de objetos, atores e processos.

O primeiro, como foi exposto nas considerações metodológicas, está associado à representação de processos e estruturas sociais (e não de eventos ou séries de eventos, os quais corresponderiam a níveis mais concretos), bem como a uma ausência de atores na representação das ações (metáforas processuais). Por exemplo:

O desafio que atualmente se coloca é o da consolidação do sistema e o reforço das suas interações, ao mesmo tempo que se promove a sua eficácia política, através de uma visão partilhada e agregadora. Pretende-se, assim, reforçar a qualidade do SI\&I e mobilizar as suas competências e capacidades científicas, técnicas e de inovação para o desenvolvimento de novos produtos e serviços, para a melhoria de produtos e processos, e para o reforço da inovação organizacional. (IAPMEI et al., 2014: 8) 
O protagonista (e não o sujeito, pois o parágrafo faz uso da construção passiva) das ações que aqui se descrevem é o Sistema de Investigação e Inovação (SI\&I). Este não é uma estrutura unitária e homogénea, mas o resultado da interação e coordenação entre instituições, atores, recursos e processos de natureza diversa. Assim, atribui-se ao "SI\&I" uma série de processos e estruturas sociais, sobre os quais recaem ações tais como "consolidação", "reforço" e "mobilização das suas competências e capacidades", sem que seja possível atribuir essas ações a atores sociais concretos, nem sequer identificar como e quem lançou o "desafio" com que começa o parágrafo.

Outros substantivos sobre os quais recaem ações são: (1) os novos "produtos", "serviços" e "processos", que são "desenvolvidos" e "melhorados"; (2) a "inovação organizacional" que é "reforçada". Também aqui não é possível identificar os sujeitos dos referidos desenvolvimentos, melhorias e reforços.

Outro exemplo deste tipo de linguagem abstrata é: "A articulação entre o nível nacional e o nível regional nas estratégias é potenciada pela interligação dos temas que atravessam o território" (IAPMEI et al., 2014: 13).

A "interligação" de temas é, ela própria, sujeito da ação de "potenciar" articulações, o que supõe uma metáfora gramatical, por um lado, e o uso de um verbo altamente abstrato ("potenciar"), por outro.

O segundo aspeto é o uso de palavras em inglês para designar objetos, atores e processos. Sobre a matéria, Rodríguez Díaz (2011) refere que são empréstimos linguísticos aquelas palavras oriundas de outras línguas "que se integram na língua recetora após um processo de adaptação fonológica e/ou morfológica" (ibidem: 11). Já os estrangeirismos, continua Rodríguez Díaz, mantêm a morfologia inicial do vocábulo importado.

Nesse sentido, é importante rever quais as palavras e expressões inglesas presentes na ENEI, desde logo para identificar se elas correspondem a empréstimos lexicais, estrangeirismos ou outro tipo de fenómeno linguístico. A seguir, apresenta-se a listagem por ordem alfabética:

Assessment of the resilience
Assisted living
Benchmarking
Bottom-up
Brainstorming
Cloud computing
Cluster
Clusterização
Coaching
Design
e-banking
e-government
Enforcement

Assessment of the resilience

Assisted living

Benchmarking

Bottom-up

Brainstorming

Cloud computing

Cluster

Clusterização

Coaching

Design

e-government

Enforcement

Engineering \& tooling
Entrepreneurial discovery process
Gap analysis
Hubs
Internet of jobs
Key enabling technologies
Know-how
Knowledge for growth
Lock-in
Net-zero energy buildings
Offshore
On-line
Parallel computing

Place-based research

Platform

Policy-mix

Public procurement

Self-discovery

Smart appliances

Smart grids

Smart homes

Smart specialization

Stakeholders

Top-down

Trustworthy ICT

Upgrade 
Dos 39 vocábulos identificados, nove correspondem a estrangeirismos, a saber: benchmarking, brainstorming, cluster, design, Internet, know-how, offshore, on-line e upgrade. Eles encontram-se incorporados no vocabulário da língua portuguesa e estão incluídos nos dicionários oficiais. As restantes palavras não cumprem a mesma condição e, à exceção da palavra "clusterização", nem têm sofrido modificações morfológicas ou fonológicas na sua apropriação por arte dos falantes de português (ou seja, tão-pouco são "empréstimos linguísticos"). Perante tal análise, importa indagar sobre qual a função linguística que desempenham as 29 expressões restantes.

Antes de mais, importa considerar que o caso do inglês não é apenas mais um exemplo de intercâmbio cultural, entre muitos outros de dimensões semelhantes. $\mathrm{Na}$ verdade, o peso cultural que tem o inglês como língua hegemónica reflete-se na grande quantidade de palavras e expressões que permanentemente procuram e ganham um lugar dentro do léxico de outras línguas. $\mathrm{O}$ aspeto decisivo neste processo é, então, "analisar a relação que essas línguas têm entre si como indício, em última instância, da relação entre ambas as comunidades de falantes. Só assim se evidenciaria a magnitude da assimetria, da desproporção” (Muñoz Martín e Valdivieso Blanco, 2006: 474).

A incorporação de hierarquias na linguagem fica completa no plano simbólico, então, quando as decisões políticas intercalam a língua própria com termos como benchmarking, que é um estrangeirismo em vários sentidos: tem origem numa língua estrangeira e num campo semântico alheio à ciência e à investigação, como é a gestão empresarial, promovendo-se desta forma o desenvolvimento por imitação. Evidências semelhantes encontram-se na presença de expressões como: "enforcement das patentes" (IAPMEI et al., 2014: 27); "lock-in estrutural" (ibidem: 29) e "resultado do entrepreneurial discovery process e de self discovery" (ibidem: 102).

A política pública é, assim, incorporada num horizonte de sentido criado pelo centro, quer em termos político-ideológicos, quer em termos de apropriação simbólica do discurso pela via da submissão linguística.

\section{Representações de ciência}

$\mathrm{O}$ anexo A da política sugere uma conceção abrangente do conhecimento:

Importa referir que o conhecimento nesta análise não é só aquele que resulta da investigação que define hipóteses e elabora teorias para a compreensão dos fenómenos, mas também aquele que visa encontrar soluções tecnológicas, de design e de organização (conhecimento codificado em publicações e patentes ou tácito, incorporado nas pessoas). Este conhecimento inclui o designado conhecimento social, tal como definido por Mokyr (2005), como o conjunto de todas as partes do conhecimento individual que 
permite uma maior especialização, profissionalização e experimentação, que a sociedade tem ao seu dispor para promover o crescimento económico. (IAPMEI et al., 2014: 103)

A principal limitação deste excerto é a definição de conhecimento social como o conjunto das "partes" do conhecimento individual e não como um processo histórico de aprendizagem socialmente construída. A esta conotação adicionam-se as características de especialização, de profissionalização e de experimentação "para promover o crescimento económico", as quais restringem o alcance do conhecimento social, assim entendido no âmbito da produção material.

Em contraste, o conceito de "sistema de inovação" enfatiza os benefícios sociais do conhecimento e não o crescimento económico como propósito fundamental. No documento escreve-se:

o conceito de sistema de inovação - entendido aqui como um conjunto de elementos, relações e atributos que contribui para a produção, difusão e exploração do conhecimento em novos produtos, processos e serviços em benefício da sociedade - foi aplicado nesta análise. (ibidem: 103)

Com efeito, a ideia de sistema de inovação visa ultrapassar o modelo linear da CTeI, ao reconhecer que ele é apenas um componente de um "modelo interativo" (ibidem: 102). No documento pode ler-se ainda: "embora o policy mix seja apresentado numa lógica linear - da formação à comercialização e ao contexto - contempla uma abordagem sistémica" (ibidem: 49).

No entanto, o que o corpus da política põe em evidência é que toda a orientação do conhecimento e a inovação, na ENEI, tem o mercado como ponto de partida (determinador de prioridades) e de chegada (indicador de sucesso).

A função social do conhecimento, tal como é concebida nesta política, reconhece que a "transferência" e a "exploração do conhecimento" têm "importantes impactos a nível de desenvolvimento económico e societal" (IAPMEI et al., 2014: 27). Todavia, logo a seguir, enfatiza-se a importância de reforçar os mecanismos de "proteção da propriedade industrial ou intelectual", referindo que "importa promover a cultura de propriedade industrial a nível, por exemplo, de competências técnicas e especializadas sobre as especificidades do sistema, da qualidade e enforcement das patentes" (ibidem).

Um bom exemplo desta priorização verifica-se na forma como o relatório aborda os problemas ambientais e o papel do conhecimento na busca de soluções para os mesmos. A este respeito, o relatório refere que "O agravamento dos problemas ambientais à escala global tende a gerar oportunidades económicas para setores, empresas e empreendedores que sejam capazes de 
propor novos produtos, processos e soluções” (IAPMEI et al., 2014: 29). Desta forma, as problemáticas ambientais, longe de serem vistas na sua dimensão social e política como um fenómeno complexo que exige respostas transdisciplinares em resultado da investigação científica, são colocadas pela ENEI como oportunidades de negócio.

De facto, o interesse na superação do modelo linear (entendido como a crença numa relação de proporcionalidade direta e mecânica entre a investigação básica, a investigação aplicada, a inovação e o crescimento económico) anteriormente referido, fica atenuado no terceiro dos objetivos estruturantes da ENEI, identificado como "A aposta em bens e serviços transacionáveis e com valor acrescentado, a internacionalização das empresas e a diversificação de mercados" (ibidem: 26). A este respeito o documento estabelece:

deverá fomentar-se a participação das empresas no processo de obtenção de conhecimento (aumentando o investimento privado em I\&D e Inovação), aumentando o peso das atividades intensivas em tecnologia e conhecimento, em especial em setores transacionáveis e internacionalizáveis, que contribuam para a alteração do perfil competitivo e para um crescimento sustentável das exportações. (IAPMEI et al., 2014: 28)

A sequência "investimento em $I \& D \rightarrow$ intensidade tecnológica nos setores económicos $\rightarrow$ alteração do perfil competitivo $\rightarrow$ crescimento das exportações" reflete claramente a natureza linear da conceção do vínculo entre conhecimento e desenvolvimento. O ponto de partida é o investimento privado e o de chegada é o mercado, sendo que esta sequência está também presente nos eixos temáticos da ENEI. Isto acontece porque a ENEI é, antes de mais, uma estratégia desenhada para promover o crescimento económico e que, nesse sentido, o conhecimento científico desempenha um papel relevante, sem ser ele o propósito último da política. Por outras palavras, a ENEI é uma política de inovação que confere grande importância à ciência, mas não é uma política de ciência.

Vários autores têm questionado a pertinência desta conceção linear da relação entre conhecimento e desenvolvimento. Caraça et al. (2009) colocam este questionamento em dois sentidos: primeiro, pondo em causa a crença na transformação automática dos investimentos feitos na investigação básica em ganhos de mercado. Em segundo lugar, sublinhando a importância dos processos de aprendizagem coletiva e da diversidade de perspetiva de todos os atores envolvidos.

Contudo, as representações de ciência presentes na ENEI têm como ponto de partida uma noção de conhecimento restringida ao conhecimento científico de tipo empírico-analítico que, numa tentativa de complexificação, abrange 
também o design e as soluções organizacionais, mas que tem sempre como propósito fundamental o crescimento económico. Com isto se negligenciam outras áreas, tais como o conhecimento científico de tipo social e humanístico, o qual, não sendo menos importante para a dinâmica social, nem sempre contribui de maneira direta e mensurável para o incremento do PIB.

De facto, o documento apresenta um escasso desenvolvimento dos temas que exigem o concurso das ciências sociais, tais como os fatores culturais e identitários e o seu contributo para o desenvolvimento do país. Estes são aspetos que abordamos seguidamente.

\section{As pessoas, a natureza e a cultura na ENEI}

A ENEI incorpora elementos relativos à cultura e considera-os pilares da visão 2020 para o SI\&I português, visando

potenciar o posicionamento de Portugal como país com capacidade científica elevada e como produtor cultural e criativo através [...] da exploração e valorização das indústrias culturais e criativas, que desenvolvem e transformam a identidade nacional, em articulação com a capacidade e o potencial do Turismo. (IAPMEI et al., 2014: 10)

No entanto, a incorporação de aspetos identitários e culturais no âmbito da inovação é colocada em termos de "exploração", "produção" e "indústria". Do mesmo modo, a natureza e as pessoas são constantemente definidas como "recursos" de cuja exploração resultam benefícios para a produtividade e para o crescimento económico. Os fragmentos a seguir ilustram e suportam esta afirmação:

a) Natureza: dos eixos temáticos que, com foi dito, operacionalizam os objetivos estruturantes da política, o eixo 4 refere-se à economia do Mar - Sistemas naturais e recursos energéticos renováveis. $\mathrm{Na}$ visão do documento, pretende-se "Maximizar o conhecimento, a valorização e a exploração dos ecossistemas, dos recursos vivos e não vivos, marinhos e energéticos do Oceano" (ibidem: 40).

b) Pessoas: a "política de recursos humanos" faz parte do policy mix ligado a esta estratégia. Esta política estabelece que "A criação de emprego científico, promovendo a inserção de recursos humanos altamente qualificados nas empresas e no setor público, desempenha um papel fulcral no esforço de valorização desses recursos" (ibidem: 50).

c) Cultura: associada à promoção de Portugal "como destino turístico de excelência" (ibidem: 44) surge a ideia de "exploração da herança cultural (património material e imaterial” (ibidem: 45). Adicionalmente, 
em articulação com a "a capacidade e o potencial do turismo" (ibidem: 10) emerge a ideia da "exploração e valorização das indústrias culturais e criativas" (ibidem: 10).

O que têm em comum estes três fragmentos é a atribuição explícita da condição de "recurso" à natureza, às pessoas e, de forma implícita, ao próprio património cultural e à criação cultural. A instrumentalização da natureza e das pessoas é uma das maiores limitações do projeto de transformação material da modernidade, sendo que presença do adjetivo "sustentável" nesta política é insuficiente para ultrapassar esta instrumentalização que está profundamente enraizada na linguagem.

- Na ENEI encontram-se outros exemplos em sentido similar e que demonstram transformação de toda expressão humana em potencial produto transacionável: "uma gestão partilhada das várias unidades do setor [turístico] em simultânea com a reabilitação urbana, permitindo o reconhecimento de Lisboa como um destino turístico para segmentos de classe alta e média alta, elevando assim o preço de Lisboa" (IAPMEI et al., 2014: 58).

- "Integrar e valorizar o património material e imaterial pela promoção/ /dinamização de indústrias culturais e criativas" (ibidem: 59).

- "Fomentar a articulação entre o turismo e as demais atividades [...] que podem beneficiar da notoriedade internacional do destino do Algarve e da procura turística de proximidade, junto de um público com capacidade para reconhecer a diferença e disponibilidade e para pagar mais por ela" (ibidem: 60).

\section{O papel da educação}

A ENEI atribui um papel nestes processos à educação, papel que é consistente com a visão geral do papel da "I\&D+I" "focada no mercado". A razão para que a educação seja considerada neste contexto reside numa das fraquezas identificadas na análise SWOT que serviu de base à formulação da política. Essa fraqueza consiste no "desajuste entre as competências produzidas no sistema educativo e as necessidades do mercado" (IAPMEI et al., 2014: 21).

A escola aparece como "produtora" de competências e estas últimas como o propósito da educação. A coerência ideológica entre esta conceção do papel da educação e a ideia das pessoas como "recursos" fica, assim, em evidência:

A aposta no reforço de competências e capacitação dos recursos humanos, surge como um importante instrumento para a inovação nos modelos de negócio atuais e futuros impondo-se como um fator de competitividade de grande relevância. Finalmente, deverá promover-se a inserção de recursos humanos altamente qualificados no 
sistema de I\&D, através da criação de emprego científico, procurando valorizar esses recursos, e o investimento em formação/investigação já realizado. (ibidem: 27)

A educação, entendida como fonte de recursos humanos competentes e, portanto, determinada pelo mercado, perde por esta via o seu caráter de consciência crítica da sociedade e limita-se à reprodução de mão-de-obra para a sua exploração como recurso, assim como dos recursos naturais e culturais. Ou seja, e utilizando as mesmas palavras presentes na ENEI, de todos os "recursos vivos e não vivos" (IAPMEI et al., 2014: 40). Esta abordagem não esgota o sentido do processo educativo que abrange também a formação moral e política, irredutível a capacidades baseadas em saberes de tipo técnico.

\section{Representações de desenvolvimento e o papel de Portugal no mundo}

$\mathrm{Na}$ política afirma-se que o "perfil de especialização da economia" tem dado alguns sinais positivos, tais como "o aumento do emprego em atividades mais intensivas em tecnologia" (ibidem: 18). Mas este incremento não é suficiente, uma vez que "a economia portuguesa apresenta um perfil de especialização com base no valor acrescentado e com base no emprego, em atividades de baixa ou média intensidade tecnológica" (ibidem).

Adicionalmente, a ENEI enfatiza a existência de fraquezas estruturais na economia portuguesa que condicionam a sua incorporação na economia-mundo. Com efeito, o que se observa no capítulo "Posição competitiva de Portugal no panorama Europeu e Internacional" é uma clara correspondência com a categoria teórica denominada de "semiperiferia". A este respeito o texto refere:

As empresas e as fileiras industriais vêem-se, muitas vezes, pressionadas concorrencialmente "por cima" e "por baixo" ficando entre dois grupos diferenciados, isto é, de um lado, as empresas do mundo mais desenvolvido vocacionadas para produtos de gama média-alta e alta suportados por fatores competitivos avançados e dotadas de organizações comerciais e, por outro lado, empresas de países que produzem nas gamas média e média/baixa com base em baixos custos de produção (nomeadamente salariais). (ibidem: 19)

A caracterização de alguns países como pertencentes ao "mundo mais desenvolvido" será comentada mais à frente. Deste excerto interessa por agora destacar o facto de a economia portuguesa estar representada como sujeita a uma posição intermédia e limitada para competir, quer com o custo da sua mão de obra (por existirem países com mão de obra mais barata), quer com a intensidade tecnológica da sua produção industrial (por existir um "mundo mais desenvolvido"). Neste caso, a semiperiferia não é definida 
em função dos benefícios que Portugal pode ter quando comparado com os países periféricos, mas é definida como uma posição de desvantagem, por igual, relativamente aos países centrais e aos países periféricos.

Ora, o que a política propõe para o país ultrapassar esta condição semiperiférica corresponde plenamente ao modelo de desenvolvimento baseado no paradigma da modernização habitualmente denominado de catching up. Por outras palavras, a ENEI propõe que Portugal deve "alcançar" os países mais "desenvolvidos".

A primeira evidência desta correspondência teórica - que é, ao mesmo tempo, política, com a ideia da modernização - é a afirmação de que existem países "mais" (e, portanto, também, "menos") desenvolvidos, como se observou no fragmento citado anteriormente. A segunda evidência é que, para os autores da política, a distância existente entre Portugal e esses países pode ser reduzida:

- "Considerado na totalidade, o SI\&I manifesta uma densidade de atores e de interações entre estes que o aproxima dos sistemas mais desenvolvidos" (IAPMEI et al., 2014: 16).

- "Portugal apresenta-se assim como um "inovador moderado", o que significa que ainda tem um longo caminho a percorrer para alcançar as economias europeias mais inovadoras" (ibidem: 17).

As críticas a esta conceção do desenvolvimento, expostas nas páginas anteriores, têm como argumento central que o subdesenvolvimento de uns países é a condição de possibilidade do desenvolvimento de outros. Por essa razão, a redução das distâncias entre uns e outros é uma impossibilidade lógica e histórica.

Finalmente, o paradigma de desenvolvimento que é expressamente assumido no documento é o da "sustentabilidade", visto que

A sustentabilidade é um conceito chave e um fator dinâmico para a estratégia coletiva, constituindo-se como uma oportunidade de diferenciação na inovação, envolvendo ganhos significativos em competitividade e quotas de mercado. Este novo paradigma de desenvolvimento [...] vai ao encontro dos temas focais da agenda europeia. (ibidem, 2014: 46)

Colocada em contexto, a sustentabilidade por um lado e a exploração dos seres "vivos e não vivos" por outro, não se excluem mutuamente, mas coexistem na ENEI. Isto, apesar da clara contradição entre um paradigma de desenvolvimento baseado na sustentabilidade (que implica conservação) e outro baseado na exploração (que se centra na extração de utilidades). 


\section{Conclusões: os propósitos e os fins desta política}

A ENEI realiza um esforço para traduzir e incorporar os propósitos da Estratégia Europa 2020 no âmbito da ciência, da tecnologia e da inovação em Portugal. Por outras palavras, a ENEI é uma tentativa de harmonizar Portugal com as visões do mundo natural e social e da atividade económica que subjazem à política europeia para a recuperação económica e para a transformação da Europa numa economia baseada no conhecimento, mais inclusiva e sustentável.

A política apresenta estratégias discursivas que incluem o uso de características linguísticas, tais como o recurso a estrangeirismos, a linguagem tecnocrática, a um alto nível de abstração dos enunciados, a metáforas lexicais e processuais, a definições persuasivas e a uma legitimação baseada no futuro utópico. Estas características, por sua vez, tornam possível a mobilização de conteúdos ideológicos que conferem uma identidade específica à política e aos seus fins.

Assim, as primeiras características linguísticas que emergiram nesta análise foram a utilização de estrangeirismos e a utilização de uma linguagem tecnocrática importada do mundo das empresas que, segundo Inozemtsev (2002), é consistente com a conceção modernizadora do desenvolvimento como catching up que inspira a confiança desta política no crescimento económico.

Destaca-se também o elevado nível de abstração acompanhado de metáforas processuais e nominalizações que caracteriza, por exemplo, a descrição que a política faz do funcionamento do sistema de investigação e de inovação. Esta descrição caracteriza-se pela ausência de atores sociais concretos, pelo que as ações são realizadas pelo próprio sistema, ou seja, por uma entidade abstrata que é, ela própria, uma síntese de atores, eventos e processos sociais.

O conhecimento que subjaz a estes processos de inovação é, por sua vez, um certo tipo de ciência que é herdeira do paradigma tradicional da experimentação ao serviço da indústria e cujos resultados se medem segundo o número de patentes. Em termos de características linguísticas, esta noção é promovida por definições persuasivas, isto é, por argumentos que são apresentados como aceções amplamente partilhadas de um termo, mas que estão politicamente condicionadas. É o caso da definição de "conhecimento social” como somatório de conhecimentos individuais cujas características mais relevantes são a especialização, a profissionalização e a experimentação.

Por sua vez, a designação dos atores sociais, do ambiente e do património imaterial como "recursos" desempenha a função linguística de legitimar a sua exploração comercial. Este recurso linguístico aprofunda o afastamento da sociedade civil em relação à esfera do conhecimento científico, promove a instrumentalização das pessoas no seio do sistema educativo e desvaloriza o território como âmbito de construção de cultura e cenário de encontro de saberes. 
As implicações lógicas também desempenham um papel importante na representação do desenvolvimento. Assim, a noção de "o mundo mais desenvolvido" (IAPMEI et al., 2014: 19) implica logicamente a existência de um mundo "menos desenvolvido", bem como a metáfora "Portugal [...] ainda tem um longo caminho a percorrer para alcançar as economias europeias mais inovadoras" (ibidem: 17) supõe, do mesmo modo, que a distância entre ambos os "mundos" pode ser encurtada. O uso da metáfora gramatical do percurso corresponde a uma representação linear e historicista do desenvolvimento.

Finalmente, a política cria uma narrativa de legitimação que consiste no relato de um futuro utópico resultado das suas iniciativas combinadas com valores individuais, desde logo quando se afirma que "O espírito empresarial contribui para a criação de emprego e para a modernização e crescimento da economia, promovendo uma nova geração de empresários com atividades de alto valor acrescentado e dirigidas ao mercado global" (ibidem: 28).

No entanto, nos primeiros anos de implementação desta estratégia de Especialização Inteligente em Portugal, a participação económica do setor industrial de alta intensidade tecnológica continua a estar abaixo da média europeia (Simões et al., 2017). Existem, desde logo, sinais positivos, tais como a existência de um número cada vez maior de profissionais altamente qualificados, assim como de um número crescente de publicações científicas em coautoria com investigadores estrangeiros.

Esta situação confere relevância ao apelo de Pinto e Pereira (2013) segundo o qual, para ultrapassar os desafios colocados pela necessidade de reforçar as relações de cooperação entre a ciência e os setores económicos, é necessário considerar a multiplicidade de fatores que tornam possível essa relação. Entre esses fatores contam-se a mudança tecnológica, a configuração dos sistemas de inovação, o seu impacto sobre o comportamento das economias nacionais e, mais importante, as complexas interações entre os atores, as instituições e o ambiente.

Portanto, ainda que se reconheça a natureza participativa do exercício de formulação da Estratégia Nacional de Especialização Inteligente, o seu caráter parcial (uma vez que está imersa numa lógica mais ampla de regulação europeia) e o seu legítimo interesse na superação das fracas relações entre os setores da ciência, da inovação e o setor produtivo, é também importante reconhecer e explicitar as opções políticas que subjazem à ideia da especialização inteligente em geral e à ENEI em particular.

Vários autores têm sublinhado que a luta pela democracia no contexto da globalização não pode negligenciar a dimensão epistémica, isto é, "a reinvenção do poder emancipador do conhecimento, com mais e melhores ciências, ciências sociais e outros saberes argumentativos" (Caraça, 2002: 209). 
Portanto, das opções políticas refletidas nas estratégias de regulação da CTeI depende a possibilidade de ultrapassar ou, pelo contrário, reproduzir as assimetrias a nível europeu entre os países centrais e os países periféricos, assim como a oportunidade de fortalecer ou debilitar as comunidades científicas enquanto atores sociais, assim como a ciência como património para o bem-estar social.

Revisto por Sofia Silva

\section{Referências bibliográficas}

Barca, Fabrizio; McCann, Philip; Rodríguez-Pose, Andrés (2012), "The Case of Regional Development Intervention: Place-Based versus Place-Neutral Approaches", Journal of Regional Science, 52(1), 134-152.

Brandão, Tiago (2012), "Portugal e o programa de ciência da NATO (1958-1974): episódios de história da 'política científica nacional”", Relações Internacionais, 35, 81-101.

Caraça, João (2002), "Os mercados, os seus saberes e as suas incertezas”, Revista Crítica de Ciências Sociais, 63, 209-219.

Caraça, João; Lundvall, Bengt-Åke; Mendonça, Sandro (2009), "The Changing Role of Science in the Innovation Process: From Queen to Cinderella?", Technological Forescasting \& Social Change, 75, 861-867.

Castro, Irina; Serra, Rita; Neves, Daniel; Nunes, João Arriscado (2013), "Oficinas de ciência: da governação da ciência e tecnologia à produção de conhecimento", Oficina do CES, 401.

Comissão Europeia (2010), União da inovação. Bruxelas: União Europeia. Consultado a 21.09.2014, em http://www.eurocid.pt/pls/wsd/wsdwcot0.detalhe?p_cot_id=7262.

Comissão Europeia (2014), "Estratégias de inovação regionais/nacionais para a especialização inteligente (RIS3). Política de coesão 2014-2020”. Consultado a 12.11.2016, em http://ec.europa.eu/regional_policy/sources/docgener/informat/2014/ smart_specialisation_pt.pdf.

Fairclough, Isabela; Fairclough, Norman (2012), Political Discourse Analysis: A Method for Advanced Students. London: Routledge.

Fairclough, Norman (2001), "Critical Discourse Analysis as a Method in Social Scientific Research”, in Ruth Wodak; Michael Meyer (orgs.), Methods of Critical Discourse Analysis. London: Sage, 121-138.

Fairclough, Norman (2003), Analysing Discourse. Textual Analysis for Social Research. London: Routledge.

FCT - Fundação para a Ciência e a Tecnologia (2013), Diagnóstico do sistema de investigação e inovação: desafios, forças e fraquezas rumo a 2020. Portugal: Ministério de Educação e Ciência. 
Fiolhais, Carlos (2011), A ciência em Portugal. Lisboa: Fundação Francisco Manuel dos Santos. Fonseca, Pedro; Ferreira, Maria João (2015), “Through Seas never before Sailed: Portuguese Government Discursive Legitimation Strategies in a Context of Financial Crisis", Discourse \& Society, 26(6), 628-711.

Foray, Dominique; David, Paul A.; Hall, Bronwyn (2009), "Smart Specialisation: The Concept", Knowledge for Growth: Prospects for Science, Technology and Innovation. Selected Papers from Research Commissioner Janez Potočnik's Expert Group. Consultado a 21.09.2014, em http://ec.europa.eu/invest-in-research/pdf/download_en/ selected_papers_en.pdf.

Foray, Dominique; David, Paul A.; Hall, Bronwyn H. (2011), "Smart Specialization: From Academic Idea to Political Instrument, the Surprising Carreer of a Concept and the Difficulties Involved in Its Implementation”, MTEI Working Papers. Lausanne: École Polytechnique Fédérale de Lausanne.

Freyre, Gilberto (1961), O luso e o trópico. Lisboa: Comissão executiva das comemorações do $\mathrm{V}$ centenário da morte do Infante $\mathrm{D}$. Henrique.

Godinho, Manuel (2007), "Indicadores de C\&T, inovação e conhecimento: onde estamos? Para onde vamos?”, Análise Social, XLII(182), 239-274.

Gonçalves, Maria Eduarda (1996), "Mitos e realidades da política científica portuguesa”, Revista Crítica de Ciências Sociais, 46, 47-67.

Gonçalves, Maria Eduarda (2001), "A importância de ser europeu: ciência, política e controvérsia sobre o risco da BSE em Portugal”, in João Arriscado Nunes; Maria Eduarda Gonçalves (orgs.), Enteados de Galileu? A semiperiferia no sistema mundial da ciência. Porto: Edições Afrontamento, 171-208.

Graham, Philip (2001), "Space: Irrealis Objects in Technology Policy and Their Role in a New Political Economy”, Discourse \& Society, 12(6), 761-788.

Habermas, Jürgen (2013a), "Política cientificada e opinão pública”, in Jürgen Habermas, Técnica e ciência como "ideologia”. Lisboa: Edições 70, 107-128 [ed. orig.: 1963].

Habermas, Jürgen (2013b), "Técnica e ciência como ideologia”, in Jürgen Habermas, Técnica e ciência como "ideologia”. Lisboa: Edições 70, 45-92 [ed. orig.: 1968].

IAPMEI - Instituto de Apoio à Pequena e Mediana Empresa e à Inovação; Fundação para a Ciência e a Tecnologia; Agência Nacional de Inovação; Programa Operacional de Fatores de Competitividade (2014), Estratégia de investigação e inovação para uma especialização inteligente. Portugal: FCT - Fundação para a Ciência e a Tecnologia. Consultado a 12.02.2015, em https://www.portugal2020.pt/Portal2020/Media/ Default/Docs/EstrategiasEInteligente/ENEI_Vers\%C3\%A3o\%20final.pdf.

Inozemtsev, Vladislav (2002), Catching up: The Limits of Rapid Economic Development. New Jersey: Transaction Publishers.

Jäger, Siegfried (2001), "Discourse and Knowledge: Theoretical and Methodological Aspects of a Critical Discourse and Dispositive Analysis", in Ruth Wodak; Michael Meyer (orgs.), Mebtods of Critical Discourse Analysis. London: Sage, 32-62. 
Laranja, Manuel (2012), "Network Governance of Innovation Policies: The Technological Plan in Portugal", Science and Public Policy, 39(5), 655-668.

Marková, Ivana (2006), "En busca de las dimensiones epistemológicas de las relaciones sociales”, in Darío Páez; Amelio Blanco (orgs.), La teoria sociocultural y la psicología social actual. Madrid: Fundación Infancia y Aprendizaje, 163-182.

Midtkandal, Ivar; Sörvik, Jens (2012), “What is smart specialisation?”, Nordregio News, 5, 3-6.

Muñoz Martín, Francisco Javier; Valdivieso Blanco, Maria (2006), "La importación lingüística en una relación asimétrica: español e inglés, dos socios desiguales”, in Luis González; Pollux Hernúñez (coords.), Actas del III Congreso "El Español, lengua de traducción”. Bruselas: Esletra, 467-494. Consultado a 21.09.2014, em https://cvc. cervantes.es/lengua/esletra/pdf/03/042_munoz-valdivieso.pdf.

Nunes, João Arriscado (2002), “As dinâmicas da(s) ciência(s) no perímetro do centro: uma cultura científica de fronteira?”, Revista Crítica de Ciências Sociais, 63, 189-198.

Nunes, João Arriscado; Gonçalves, Maria Eduarda (2001), Enteados de Galileu? A semiperiferia no sistema mundial da ciência. Porto: Edições Afrontamento.

Oliveira, Pedro (2015), "O contributo dos atores políticos e das instituições regionais para uma especialização inteligente nas áreas rurais: o caso do Vale do Tejo”, VI Congresso de Estudos Rurais. Lisboa: ICS-UL - Instituto de Ciências Sociais da Universidade de Lisboa.

Pinto, Hugo; Pereira, Tiago (2013), "Efficiency of Innovation Systems in Europe: An Institutional Approach to the Diversity of National Profiles", European Planning Studies, 21(6), 755-779.

Reisigl, Martin (2008), “Analyzing Political Rhetoric”, in Ruth Wodak; Michael Krzyzanowski (orgs.), Qualitative Discourse Analysis in the Social Sciences. London: Palgrave Macmillan, 96-120.

Rodríguez Díaz, José Antonio (2011), Anglicismos y germanismos en el lenguaje de la publicidad del español peninsular contemporáneo (1998-2007). Tese de Doutoramento apresentada na Facultade de Filoloxía de la Universidad de Santiago de Compostela, Santiago de Compostela, Espanha.

Rollo, Fernanda; Meireles, Paula; Ribeiro, Madalena; Brandão, Tiago (2012), "História e memória da ciência e da tecnologia em Portugal: o arquivo da ciência e tecnologia da Fundação para a Ciência e a Tecnologia”, Boletim do Arquivo da Universidade de Coimbra, XXV, 233-261.

Roque, Ricardo (2001), Antropologia e império: Fonseca Cardoso e a expedição à Índia em 1895. Lisboa: Imprensa de Ciências Sociais.

Santos, Anabela; Serrano, Maria Manuel; Neto, Paulo (2015), “Análise da eficácia, eficiência e valor acrescentado de políticas públicas place-based: uma aplicação a territórios rurais”, Revista de Economia e Sociologia Rural, 53, 33-48.

Santos, Boaventura de Sousa (1978), "Da sociologia da ciência à política científica”, Revista Crítica de Ciências Sociais, 1, 11-56. 
Simões, Vitor; Godinho, Manuel; Sanchez-Martinez, Miguel (2017), "Relatório por país de 2016 do Observatório RIO: Portugal”. Luxemburgo: União Europeia.

So, Alvin (1990), Social Change and Development: Modernization, Dependency and World-System Theories. London: Sage.

Van Dijk, Teun (2001a), "Multidisciplinary CDA: A Plea for Diversity”, in Ruth Wodak; Michael Meyer (orgs.), Methods of Critical Discourse Analysis. London: Sage, 95-120.

Van Dijk, Teun (2001b), "Critical Discourse Analysis”, in Deborah Schiffrin; Deborah Tannen; Heidi E. Hamilton (orgs.), The Handbook of Discourse Analysis. Oxford: Blackwell Publishers, 352-371.

Wallerstein, Immanuel (1995), Abrir las ciencias sociales. Informe de la comisión Gulbenkian para la reestructuración de las ciencias sociales. México: Siglo XxI.

Wallerstein, Immanuel (1974), The Modern World-System I: Capitalist Agriculture and the Origins of the European World Economy in the Sixteenth Century. New York: Academic Press.

Wallerstein, Immanuel (1979), The Capitalist World-Economy: Essays. Cambridge: Cambridge University Press.

Wallerstein, Immanuel (1991), Unthinking Social Science. Cambridge: Polity Press.

Wallerstein, Immanuel (2005), Análisis de sistemas-mundo: una introducción. México: Siglo XXI.

Wodak, Ruth (2001), "What Critical Discourse Analysis Is about: A Summary of Its History, Important Concepts and Its Developments”, in Ruth Wodak; Michael Meyer (orgs.), Methods of Critical Discourse Analysis. London: Sage, 1-14.

Artigo recebido a 05.01.2017

Aprovado para publicação a 20.03.2018

\section{Maria Cristina Ovalle Almanza}

Facultad de Ciencias Humanas y Artes, Departamento de Ciencias Sociales y Jurídicas, Universidad del Tolima

Altos de Santa Elena, 730002 Ibagué, Colombia

Contacto: mcovallea@ut.edu.co

\section{Pedro Miguel Moreira da Fonseca}

Centro de Administração e Políticas Públicas do Instituto Superior de Ciências Sociais e Políticas, Universidade de Lisboa

Rua Almerindo Lessa, 1300-663 Lisboa, Portugal

Contacto: pfonseca@iscsp.ulisboa.pt 
Critical Discourse Analysis of the
National Research and Innovation
Strategy for an Intelligent
Specialization of Portugal 2014-2020

The article presents a critical discourse analysis (CDA) applied to the National Research and Innovation Strategy for an Intelligent Specialization of Portugal 2014-2020 (NSIE). The purpose is to interpret the representations about scientific and technological knowledge underpinning the NSIE as well as the relationship between these representations and the paradigm of development promoted by the policy paper and its correspondence with the representations of nature, society and education. The work is based on the world-systems analysis as a theoretical perspective that allows the articulation between the discursive dimension and the normative critique, as well as to identify the presence of a linear conception of development consistent with the idea of catching up; the representation of people, nature and culture as resources as well as a notion of scientific knowledge as a continuum of experimentation, discovery and commercialization. Finally, it allowed us to recognize in the NSIE a self-representation of Portugal compatible with the theoretical category of semi-periphery.

Keywords: critical discourse analysis; innovation policy; Portugal; science and technology policy; scientific knowledge.

\section{Analyse critique du discours portant sur la Stratégie Nationale de Recherche et d'Innovation pour une Spécialisation Intelligente du Portugal 2014-2020}

Cet article procède à une analyse critique du discours portant sur la Estratégia Nacional de Investigação e Inovação para uma Especialização Inteligente de Portugal 2014-2020 (ENEI) [Stratégie Nationale de Recherche et d'Innovation pour une Spécialisation Intelligente du Portugal 2014-2020]. Notre propos est d'interpréter les représentations ayant trait à la connaissance scientifique et technologique sous-jacentes à l'ENEI et ses relations avec le paradigme de développement qu'il promeut, en cherchant à débattre des rapports avec les représentations de la nature, de la société et de l'éducation. Le travail repose théoriquement sur l'analyse des systèmes-monde afin d'articuler la dimension discursive avec la critique normative. L'analyse a permis d'identifier la présence d'une conception linéaire du développement (catching up), d'une représentation des personnes, de la nature et de la culture comme des ressources, tout autant que d'une notion de la connaissance scientifique comme un continuum d'expérimentation, de découverte et de commercialisation. Finalement, nous avons identifié une autoreprésentation du Portugal compatible avec la catégorie théorique de la semi-périphérie.

Mots-clés: analyse critique du discours; connaissance scientifique; politique d'innovation; politique scientifique et technologique; Portugal. 